\title{
A identidade semântica da preposição EM
}

DOI: http://dx.doi.org/10.21165/el.v48i3.2219

Elizabeth Gonçalves Lima Rocha'

\section{Resumo}

Propomo-nos, neste trabalho, a discutir aspectos relacionados à identidade semântica da preposição EM, a fim de descrever, para além de sua variação cotextual, o fenômeno que se encontra em seu fundamento. O trabalho organiza-se em três partes. Inicialmente, apresentamos certos estudos gramaticais que descrevem o semantismo da preposição EM na construção das representações espaciais. Na segunda parte deste trabalho, expomos os princípios que orientam nossa investigação, qual seja, o referencial teóricometodológico da Teoria das Operações Enunciativas. Por fim, na terceira parte, mostramos que a (im)possiblidade de certas representações espaciais no uso do EM deve-se a uma propriedade intrínseca a esse item que revela uma forma abstrata extraída das análises dos dados linguísticos.

Palavras-chave: semântica preposicional; preposição EM; representações espaciais; identidade semântica.

1 Universidade Federal do Piauí (UFPI), Teresina, Piauí, Brasil; bethroccha@hotmail.com; https://orcid.org/0000-0001-5050-7334 


\title{
The semantic identity of the preposition EM
}

\begin{abstract}
In the present paper, we propose to discuss some aspects related to the semantic identity of the preposition 'EM', in order to describe the phenomenon that is at its foundation beyond its cotextual variation. The paper is organized in three parts. First, we present certain grammatical studies that describe the semantics of the preposition "EM" in the construction of spatial representations. Secondly, we show the principles that guide our investigation, that is, the theoretical-methodological reference of the Theory of Enunciative Operations. Finally, in the third part, we show that the (im)possiblity of certain spatial representations when using "EM" is due to an intrinsic characteristic of this preposition, which reveals an abstract meaning taken from the analyzes of the linguistic data.
\end{abstract}

Keywords: prepositional semantics; preposition EM; spatial representations; semantic identity.

\section{Introdução}

O objetivo deste artigo é, considerando-se o domínio semântico da construção do espaço na enunciação linguística, descrever a variação cotextual ${ }^{2}$ da preposição EM, quer dizer, precisar quais as representações espaciais implicadas nos diversos cenários enunciativos aos quais esse marcador se integra, e, para além disso, propor uma hipótese que responda por sua invariância de sentido, quer dizer, determinar os princípios organizadores que presidem a elaboração de tais representações. Para tanto, num primeiro momento, expomos criticamente os resultados de trabalhos ligados à problemática que se tem em vista; num segundo momento, expomos nossos princípios metodológicos e, finalmente, procedemos à análise de enunciados que baseará nossos próprios resultados, os quais são relativamente distantes dos trabalhos aqui apresentados.

A exposição crítica dos trabalhos gramaticais não será aqui exaustiva, o que significa que nos atemos somente a alguns autores relevantes. As obras que abordamos aqui podem ser divididas em dois grandes grupos. O primeiro reúne os trabalhos que podem ser considerados dentro de uma perspectiva tradicional. Escolhemos, como ilustração dessa primeira perspectiva, a Gramática normativa da língua portuguesa (LIMA, 2003) e a Nova gramática do português contemporâneo (CUNHA; CINTRA, 2001). O segundo grupo inclui um trabalho que se insere na perspectiva da gramática funcionalista, exatamente a Gramática de usos do português (NEVES, 2011).

2 Entenda-se por variação cotextual a variabilidade de ambientes linguísticos nos quais uma unidade qualquer da língua pode configurar. 


\section{A preposição EM na perspectiva tradicional}

As preposições na Gramática normativa da língua portuguesa definem-se como "palavras que subordinam um termo da frase a outro - o que vale dizer que tornam o segundo dependente do primeiro" (LIMA, 2003, p. 180). Nessa definição da categoria preposição, Lima indica seu papel sintático na construção da frase pelo destaque da função de subordinação de um termo a outro. Com respeito à exposição dos usos e significados das preposições, o autor descreve as relações por elas estabelecidas, explicitando os valores que denotam. No que diz respeito ao papel da preposição EM na construção do espaço, o autor se limita a assinalar o valor lugar onde (interior e exterior): O chá estava na mesa. (LIMA, 2003).

A Nova gramática do português contemporâneo, de Cunha e Cintra, por seu turno, define semelhantemente a preposição, segundo sua "função", como "palavras invariáveis que relacionam dois termos de uma oração, de tal modo que o sentido do primeiro (antecedente) é explicado ou completado pelo segundo (consequente)" (CUNHA; CINTRA, 2001, p. 555). Os autores explicam que mesmo apresentando uma grande variedade de usos diferenciados, pode-se estabelecer para cada uma das preposições uma significação fundamental, cuja marca é a expressão "de um movimento ou uma situação daí resultante" (CUNHA; CINTRA, 2001, p. 556). O conceito "situação" indica a falta de movimento na relação estabelecida. Segundo os autores, tanto o movimento quanto a situação "podem ser considerados com referência ao espaço, tempo e noção" (CUNHA; CINTRA, 2001, p. 557). No caso da preposição EM, e considerando-se somente o domínio do espaço, o conteúdo significativo fundamental se descreve como: 1-movimento = "superação de um limite de interioridade, alcance de uma situação dentro de": Os Garcia entraram em casa calados; 2-situação = "posição no interior de, dentro dos limites de, em contato com, em cima de": Ângelo estava estirado na casa (CUNHA; CINTRA, 2001, p. 570-571).

Comparados, veem-se algumas diferenças entre o trabalho de Lima (2003) e o dos dois autores ora considerados. Na descrição uso espacial da preposição EM, apresentada por Lima, há certa ausência de especificação e precisão, já que apenas indica o valor lugar onde (interior e exterior), sem se ocupar da diversidade das representações espaciais implicadas, tampouco do sentido unitário que subjazeria a tais representações. Cunha e Cintra são menos sumários, pois afırmam que todas as preposições, inclusive a preposição EM, possuem um conteúdo significativo fundamental - movimento e situação -, privilegiando-se os valores de "interioridade" e "contato" na construção das representações espaciais pela preposição EM.

\section{A preposição EM na perspectiva funcionalista}

Já na Gramática de usos do português (NEVES, 2011), renovam-se as classificações e multiplicam-se as caracterizações descritivas dos itens que compõem essa classe 
justamente porque a autora lança mão de exemplos retirados da própria língua em uso, alargando-se assim o corpus de investigação. As preposições, na obra, atuam funcionalmente na "junção dos elementos do discurso, isto é, ocorrem num determinado ponto do texto indicando o modo pelo qual se conectam as porções que se sucedem" (NEVES, 2011, p. 601). Com respeito à função sintática e à relação semântica de EM, relativamente à construção do espaço, lê-se, na referida gramática, que essa preposição "estabelece relações semânticas no sintagma (adjunto): EM+sintagma nominal" e estabelece uma "relação de circunstanciação de lugar onde (locativo, não diretivo)" (NEVES, 2011, p. 675, grifo do autor), a qual se deixa classificar em dois tipos: "1-sem movimento, subclassificada como (1a) localização na superfície (na superfície de, sobre, em cima de: João lia na cama obras pornográficas); (1b) localização na interioridade (no interior de, dentro de: Ele dormiu na sala até o nascimento da quarta filha); (1c) situação medial (no meio de, entre: Era só ele se afastar de casa, sentia-se dotado da maior potência e, de volta, com a bem querida nos braços); 2-com movimento, subclassificada como (2a) localização na superfície (em cima de, sobre, na superfície de: Sentamo-nos no banco do candelabro e começamos a anotar os achados); (2b) ponto de contato (num ponto de: Os homens se puseram atrás de mim e um deles me tocou no ombro); (2c) contiguidade (ao longo de: Passei a mão em suas coxas)" (NEVES, 2011, p. 675-676, grifos do autor).

Observa-se que a abordagem de Neves é mais detalhada do que as duas já referidas, consideradas a multifuncionalidade dos itens e a diversidade dos usos. De fato, como já afirmamos, Lima (2003) limita-se a indicar o valor lugar onde (interior e exterior), sem maiores considerações sobre a especificidade das representações espaciais construídas, ao passo que Cunha e Cintra (2001) são mais objetivos ao estabelecerem o conteúdo significativo da preposição EM, ressaltando os valores de "interioridade" e de "contato". Esses resultados, entretanto, são restritos se confrontados com a análise de Neves, em que a autora identifica os tipos com e sem movimento, que se desdobram; o primeiro nos valores "localização na superfície", "interioridade", "situação medial (no meio de)" e o segundo nos valores "localização na superfície", "ponto de contato" e "contiguidade". Portanto, a autora chega a um detalhamento mais preciso e específico das representações espaciais implicadas no uso da preposição EM.

Com esse maior refinamento descritivo, a obra de Neves torna-se uma obra de referência necessária e fundamental para o tratamento da variação cotextual da preposição EM, e, sem dúvida, também de outros itens. Avançamos, aqui, relativamente a essa classificação, algumas considerações que, pensamos, podem contribuir para maior exatidão descritiva desse item preposicional. Em primeiro lugar, parece-nos ser dispensável a separação dos valores localização na superfície e ponto de contato, que nos parecem equivalentes, podendo ambos serem reunidos sob a rubrica "contato". De fato, os exemplos dados pela autora (Sentamo-nos no banco e Tocou no ombro) parecem remeter a uma relação que indica contato direto. Em segundo lugar, pensamos, ainda, que o valor situação medial, avançado por Neves, se deixa englobar pelo valor interioridade, já que "em meio de" remete a uma zona constituída por limites na qual o termo determinado é localizado. Com efeito, 
observe-se que no exemplo listado por Neves, Com a bem querida nos braços, EM pode ser substituído por dentro de. Por fim, acreditamos, como mostraremos com detalhes adiante, que EM não sirva, precisamente, à construção da representação espacial contiguidade, papel que parece caber às preposições DE e A. De fato, diz-se O livro está do lado da caixa ou ainda O livro está ao lado da caixa, e não *O livro está no lado da caixa. Aliás, o exemplo de contiguidade, dado por Neves (Passei a mão em suas coxas), remete, preferencialmente, a nosso ver, à ideia de contato.

Ademais, a autora não toca o problema da unidade de sentido do marcador EM, embora anuncie que, na descrição dos usos da preposição, seu sentido unitário seria avaliado (NEVES, 2011). Nesse sentido, Romero (2013, p. 150) já havia observado que o empreendimento de Neves carece de uma abordagem que contribua: "[...] para o desenvolvimento dos estados atuais dos trabalhos, por não ser fornecido um formato de descrição unitário da preposição que responda pela variação observada em seu próprio uso ou por se deixar de fora, nas explicações, um certo número de usos".

Em suma, nas análises que compõem a Gramática dos usos do português, "não se explicita o que se entende por significado unitário da preposição, nem de que maneira esse significado unitário contribui para a construção da relação semântica estabelecida" (ROMERO, 2013, p. 150). Há, portanto, na obra, conforme já indicado, uma descrição cuidadosa e detalhada dos inúmeros empregos da preposição e uma discriminação das representações espaciais acarretadas pelo uso da preposição EM, porém não há elementos que justifiquem porque esse item linguístico integra essas e não outras construções representacionais espaciais específicas.

\section{Variação e identidade semântica para a Teoria das Operações Enunciativas}

No referencial por nós adotado, a saber, a Teoria das Operações Enunciativas (doravante TOE), os enunciados constitutivos dos textos não possuem um significado a priori; tal significado que Ihes é atribuído é, antes, construído por operações decorrentes das unidades que o constituem. Não há, pois, somatória de sentidos intrínsecos às unidades linguísticas que resultariam em um sentido do que se enuncia. Em outras palavras, os enunciados textuais que materializam a atividade de linguagem remetem não a valores que lhes sejam inerentes, não à mobilização de um referente externo, mas ao que se conhece por valor referencial, um valor que não é "exterior ao enunciado, mas é engendrado pelo próprio enunciado" (FRANCKEL, 2011, p. 45, In: DE VOGÜÉ, FRANCKEL, PAILLARD, 2011).

Para a TOE, o sentido não é um dado estocado do qual se lança mão, mas "é considerado como determinado e construído pelo material verbal que lhe dá corpo, ou seja, pelas unidades da língua organizadas segundo regras sintáticas e entonacionais" (FRANCKEL, 2011, p. 16), em suma, o sentido é resultado das operações enunciativas. 
A TOE se destaca como uma teoria voltada para a questão da variação e da invariância semântica das formas linguísticas, ou seja, é uma teoria que visa principalmente a exploração de questões que envolvem a variação das formas linguísticas e a descoberta dos princípios que sustentam a variação dessas formas, ou seja, sua unidade de sentido.

É exatamente essa problemática que está no cerne do vasto programa de pesquisa proposto por Antoine Culioli (1990, p. 115-116, tradução nossa):

A análise de um marcador (entendido não no sentido de uma etiqueta, mas de marcador de operação ou eventualmente de polioperação) deve lograr uma representação formal com características estáveis e controladas. A partir dessa representação formal, que eu chamo de forma esquemática, constituemse formas suplementares que são, no fundo, deformações da forma de base. A questão é compreender a organização desses dispositivos deformáveis ${ }^{3}$.

Essa citação traz conceitos fundamentais para a explanação que ora se coloca. Primeiro, o conceito de marcador, que preferimos ao de preposição. De fato, "preposição" remete a uma definição de ordem puramente morfológica e sintática, o que impede que formas evidentemente semelhantes do ponto de vista do seu funcionamento semântico, como a preposição EM e o prefixo EN ${ }^{4}$, sejam tratadas conjuntamente, como faremos nas análises a seguir. Por outro lado, o conceito de marcador implica uma mudança de atitude teórica frente ao fenômeno da linguagem. Isso porque marcador exclui qualquer ideia de significação mental ou referencial da qual a forma linguística seria o suporte, uma vez que nos leva a considerar os itens da língua, que se agenciam a outros itens na formação de um enunciado, como traços de operações às quais não se tem acesso por observação direta, mas que podem ser formalizados por meio do tratamento metalinguístico desses mesmos itens.

Em segundo lugar, o texto de Culioli mobiliza a ideia de uma forma abstrata de base, da qual as formas linguísticas empíricas seriam deformações materializadas na dinâmica intersubjetiva de produção e reconhecimento de enunciados. Este segundo ponto remete explicitamente ao problema da descrição da multiplicidade cotextual dos itens linguísticos e da determinação da unidade de sentido subjacente a essa multiplicidade que sustenta essa variação. A descrição dessa multiplicidade levanta o problema de saber por que certo marcador remete a operações específicas, com exclusão de outras,

3 No original: "L'analyse d'un marqueur (entendu non pas au sens d'étiquette, mais de marqueur d'opération ou éventuellement de polyopération) doit aboutir à une représentation formelle ayant des caractéristiques stables et contrôlables. A partir de cette représentation formelle, que j'appelle forme schématique, se constituent des formes supplémentaires qui sont, en fait, des déformations de la forme de base. La question est de comprendre l'organisation de ces dispositifs déformables".

4 Representamos por EN o conjunto de variantes referentes ao referido prefixo: en-, em-, e- 
ou seja, por que constrói tais e tais representações e não diversamente. Assim sendo, a TOE se distancia de outras perspectivas linguísticas, a respeito das quais se encontram, nos próprios trabalhos de Culioli (1999b), menções restritivas, com referência ao mero descritivismo classificatório das abordagens gramaticais (CULIOLI, 1999b).

Vale, por fim, assinalar que, no que se refere à metodologia, por ser uma teoria que observa e manipula dados empíricos, busca-se, na TOE, inicialmente constituir uma classe de fenômenos linguísticos por famílias de enunciados em relação parafrástica a fim de formular problemas locais, a partir da possibilidade e impossibilidade de ocorrências linguísticas, e avançar soluções razoáveis que levem em questão saber se há uma razão para a boa ou má formação dos enunciados examinados. Num segundo momento, propõese uma solução (que pode ser provisória, uma vez que podem surgir dados que coloquem novos problemas) para o fato estudado, levantando-se hipóteses que manifestem a razão da possibilidade ou impossibilidade das ocorrências e cuja formulação descreve as operações abstratas que sustentam a materialidade dos enunciados tal como ela se vê expressa, operações das quais o agenciamento dos enunciados é justamente o traço.

\section{Análise da variação cotextual da preposição EM}

Na medida em que nos restringimos, por meio do uso da preposição EM, à construção da localização de algo no espaço, partimos de um conjunto restrito de enunciados em que se observa a sequência ESTAR EM e que servem de resposta à pergunta elaborada por Onde? Tecemos, ainda, algumas considerações sobre o emprego dessa forma como prefixo EN pelo fato de, nos exemplos considerados, haver um diálogo interessante com o assunto tematizado, na medida em que EM preposição e EN prefixo apontam para operações semelhantes de localização de algo no espaço. A abordagem conjunta da preposição e do prefixo se insere numa perspectiva transcategorial que ultrapassa os limites da classificação gramatical, já que esta, ao usar critérios sintáticos e morfológicos na elaboração da taxionomia, separa EM e EN sem atentar para suas evidentes equivalências semânticas.

A sequência ESTAR EM dá origem a enunciados em que se verificam, entre outros, valores de localização espacial - os únicos tratados aqui -, como no enunciado (1) O livro está na caixa. Enunciados que localizam um objeto no espaço produzem cotextos de resposta a perguntas do tipo Onde?, tal como: Onde está o livro? Trata-se de uma interrogativa em que a existência do objeto, no caso livro, não é posta em questão. Fica claro, por meio do emprego de onde, que o livro deve estar em algum lugar, mas que não se sabe exatamente qual é esse "algum lugar". Onde é, desse modo, traço da operação de percurso, que consiste em "percorrer todos os valores ou operações possíveis em um dos lugares duma relação com $n$ lugares, sem que se queira ou se possa distinguir algum" (CULIOLI, 1999b, p. 119). Assim, considerando-se a sequência O livro está em ( ), qualquer que seja o elemento selecionado no percurso do domínio virtual que venha para especificá-lo, não 
há critério de escolha que preencha o espaço vazio da localização. É dessa forma que se caracterizam os enunciados interrogativos, enunciados através dos quais se delimita, por abstração, o conjunto dos possíveis. Nesse cenário, certos enunciados são possíveis como resposta.

(01) O livro que você procura está encaixotado.

O enunciado acima preenche o vazio do localizador - O livro está em ( ) - por meio de uma forma prefixada (encaixotado). Observa-se que, no termo encaixotado, o prefixo EN é traço da mesma operação de localização no espaço realizada em agenciamentos que incluem a preposição EM. Está encaixotado aproxima-se, portanto, de Está na caixa, ambos podendo ser parafraseados por Está dentro da caixa. EN prefixo é, dessa maneira, o marcador por excelência de uma zona de interioridade ao situar o localizado no interior do localizador.

Notemos, contudo, que Está encaixotado não se reduz necessariamente à mera assinalação de "algum lugar", podendo significar algo mais do que "no interior da caixa". Isso fica claro se simularmos um contexto em que não se parte da pergunta Onde?, mas, sim, da pergunta Como?, tal como se observa abaixo:

(2) Os livros, como estão? Ainda bagunçados?

Não, estão encaixotados.

Encaixotado, em (2), para além de uma localização espacial, remete a uma espécie de ordenação. Nesse caso, pode ser combinado com marcas que fazem variar o grau de ordem, como a marca perfeitamente (Estão perfeitamente encaixotados), a qual seria imprópria se se pretendesse indicar apenas a localização do objeto. Por conseguinte, encaixotado pode tanto situar o localizado no interior do localizador como remeter a certo grau de arranjo, o que leva a pensar que a zona de interioridade distinguida com EN remete tanto a relações de localização espacial, quanto a especificações de natureza qualitativa, isto é, a relações que dizem respeito ao modo.

No primeiro caso, é possível discernir dois tipos de interioridade espacial. Por um lado, EN discrimina uma zona interior que estabelece a relação de continente/conteúdo, como se verifica em encaixotado. Por outro lado, EN também funciona com termos que permitem distinguir uma zona interior correspondente à ideia de invólucro ${ }^{5}$ e, nesse caso, teríamos, entre outros, engaiolado.

50 estudo desenvolvido por Franckel e Paillard (2007) a respeito de dans guarda importantes considerações sobre a distinção dessas zonas. 
No segundo caso, EN distingue uma zona de interioridade que remete a especificações de natureza qualitativa, a exemplo da ocorrência encaixotado no sentido de conforme certo arranjo, e de encadernado. No exemplo de encadernado, o localizador (caderno) atrai, por meio de EN, o localizado (p. ex. A tese), não para situá-lo dentro do caderno, mas para situá-lo em certa disposição evocada por caderno (estar com as folhas unidas num volume, em geral com capa).

Nesse sentido, uma forma tal como *emesado não é atestável, em um contexto de resposta à pergunta Onde?, pois mesa não remete a zonas de contenção ou envolvimento, mas a uma superfície chapada que exclui a localização no interior. No entanto, ela se coaduna com a preposição EM numa operação de localização que remete ao contato (O livro está na mesa). Assim, a possibilidade do uso do prefixo EM tem a ver, necessariamente, com as propriedades lexicais do termo localizador.

O livro que você procura está na caixa.

O enunciado acima, como já apontamos, pode ser interpretado como equivalente ao enunciado que se agencia com encaixotado, já que também é marca da operação de localização no espaço interior, podendo ser parafraseado por O livro está dentro da caixa. Porém, a análise mostra que EM preposição extrapola os limites da interioridade, à qual EN parece se reduzir. De fato, o livro está na caixa pode perfeitamente remeter a uma relação de contato, significando O livro está sobre a caixa, isto é, o livro está na parte superior da caixa, interpretação impossível no caso de O livro está encaixotado. Essa ambiguidade fica mais evidente ainda se considerado um enunciado como O livro está no criado-mudo, em que o objeto livro pode se localizar seja em cima do criado-mudo, seja no seu interior. Há, portanto, no marcador EM (preposição), comparativamente a EN (prefixo), além do valor interioridade, a representação de dois objetos que se tocam, no sentido de que num deles, o localizador, distingue-se uma zona epidérmica que serve de apoio para o quedar-se do localizado. Nesse sentido, EM agencia-se sem problemas com mesa (O livro está na mesa), o que não ocorre, como já afirmamos, com EN (*0 livro está emesado), já que mesa é espaço que evoca uma superfície chapada, propícia à situação de repouso do localizado, e não um espaço que remete à relação continente/conteúdo, nem tampouco à ideia de invólucro.

O livro está em cima/embaixo da caixa.

Em relação a tais enunciados, alargam-se as representações espaciais em jogo, já que, por meio de em cima e embaixo, é possível tanto construir o contato, seja superior seja inferior, quanto a distância relativa, também superior e inferior, dependendo da natureza do localizador. De fato, o livro está em cima/embaixo da caixa significa ou que o livro repousa sobre a caixa (em cima) ou que esta repousa sobre o livro, cuja localização seria embaixo, havendo, na relação entre localizado e localizador, um contato de superfícies. 
Mas o enunciado constituído com tais marcadores também pode significar que o localizado se destaca do localizador. Dessa maneira, o livro está embaixo da mesa não implica necessariamente contato, porém exige que haja proximidade, devido à noção do localizador e as propriedades que implica. Por outro lado, a comparação entre em cima/embaixo com acima/abaixo mostra como os marcadores EM e A constroem representações espaciais bem diferentes no eixo vertical, já que o primeiro remete aos valores de contato e proximidade e o segundo ao valor de distanciamento. É o que fica explícito se confrontados os enunciados A lâmpada está em cima de nós e As estrelas estão acima de nós. Em ambos os casos, lâmpada e estrelas se destacam verticalmente do localizador, mas, no primeiro, mantendo uma vizinhança e, no segundo, um afastamento.

(05) O livro está do lado da caixa/O livro está ao lado da caixa/*O livro está no lado da caixa

O conjunto de enunciados acima mostra que apenas EM, comparado aos marcadores A e DE, não serve à construção da relação lateral próxima, ou seja, da relação de contiguidade. Observa-se que Ao lado da caixa e do lado da caixa podem, ambos, ser parafraseados por junto à caixa, sem que, porém, essa localização implique, necessariamente, contato. A má formação de um enunciado como *o livro está no lado da caixa mais uma vez diz respeito às propriedades do espaço localizador. Lado é uma espacialidade absolutamente relativa (o lado é sempre lado de alguma coisa), de tal forma que tanto ao lado de quanto do lado de remetem a uma vinculação de mera vizinhança entre os termos envolvidos. Ora, o marcador EM exclui a relação de contiguidade vizinha, sem contato necessário, constituída por ao lado de ou do lado de, daí a impossibilidade do enunciado *o livro está no lado da caixa. Isso não é contradito pela aceitabilidade de um enunciado como O coração está no lado esquerdo do peito, já que nele desaparece o valor de contiguidade do termo lado, o qual se transforma em espaço vazado, já que é parte da caixa torácica dentro da qual se localiza o coração.

\section{O livro está na frente da caixa}

O enunciado acima produz, de forma evidente, o valor de localização na proximidade, podendo ser substituído por O livro está perto da caixa. Comparemos, nesse sentido, os enunciados Berger voltou a ficar em terceiro, mas estava a uma grande distância de Airton Senna e Piquet era o sexto no grid com Senna e Prost poucos metros, apenas, na sua frente; o segundo enunciado, que representa uma aproximação entre localizador e localizado, constrói um valor referencial inverso do primeiro, que remete à ideia de distanciamento entre os termos postos em jogo, no eixo transversal. Esses dois exemplos e suas diferenças podem ser aproximados das construções, já abordadas, em cima e acima, como o mesmo resultado analítico, já que em cima aponta, no eixo vertical, para uma localização de contato ou proximidade e acima implica necessariamente afastamento. 
As análises acima mostraram que a preposição EM se presta a operar a localização espacial, distinguindo-se os valores de interioridade (encaixotado, na caixa), contato (na mesa, em cima da mesa) e proximidade (na sua frente). Por outro lado, deixam evidente que com EM não se constrói o valor contiguidade ( ${ }^{\star} O$ livro está no lado da caixa), cabendo esse papel, antes, a preposições DE e A (O livro está do/ao lado da caixa). Além disso, segundo as análises, EM tampouco serve à representação do distanciamento, função efetuada pela preposição A ( ${ }^{*}$ Está em muitos metros daqui, Está a muitos metros daqui). Ora, esses problemas, provenientes do tratamento analítico dos enunciados, segundo nossa hipóteses, podem receber uma solução razoável se considerarmos que a preposição EM é dotada de uma espécie de propriedade "imã", o que significa que esse marcador funcionaria num entre-dois ( $X$ e $Y$ ), ou seja, entre os termos antecedente e consequente, de tal maneira que $Y$, introduzido por $E M$, exerce uma força sobre $X$, atraindo-o para seu domínio.

A propriedade ímã de EM torna-se evidente ainda em enunciados como Os livros estão em torno da mesa, no qual a vizinhança, com um núcleo exercendo força de atração, é a principal representação construída. Em torno e seus similares (em redor, em volta etc.) combinam-se somente com o contínuo, ou seja, com o que não cessa o que, por um lado, inclui seu agenciamento com nomes que referem objetos passíveis de partição ${ }^{6}(0$ leite espalhou-se em torno do prato), e, por outro lado, exclui seu agenciamento com nomes que referem objetos discretizáveis ${ }^{7}$ quando singulares ( ${ }^{\star} \mathrm{O}$ livro está em torno da mesa), exigindo, neste último caso, o plural (Os livros estavam em torno da mesa).

Portanto, conforme as análises acima, que partem de um conjunto de enunciados em que se observa a sequência ESTAR EM, e que servem de resposta à pergunta elaborada com onde?, podemos distinguir, num tratamento conjunto de EM preposição e EN prefixo, os seguintes valores de localização espacial.

1: Interioridade: Ex. Na caixa, encaixotado.

2. Contato: Ex. Em cima da caixa, embaixo da caixa.

3. Proximidade: Ex. Na frente da caixa.

4. Gravitação: Ex. Em torno da mesa.

6 Nomes que admitem mais facilmente expressões que designam parte do todo, como um pouco de, por exemplo.

7 Nomes que admitem mais facilmente o determinante um(a). 
Considerando esses valores de localização espacial construídos por EM e aqueles impossíveis de serem construídos com esse marcador, podemos avançar a seguinte formalização expressa na figura a seguir:

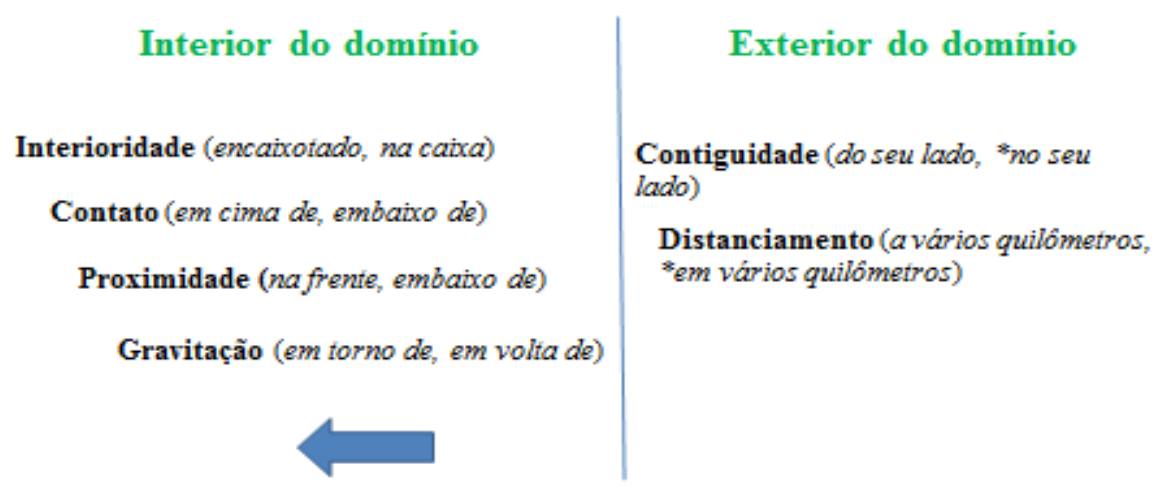

Figura 1. Domínio da localização espacial operada com estar em

Fonte: Elaboração própria

A nossa hipótese no que diz respeito à formulação da identidade do EM na elaboração das representações espaciais se formaliza em termos de propriedade ímã. Essa propriedade é o princípio que regula a construção das representações descritas (interioridade, contato, proximidade, gravitação) e não de outras (contiguidade, distanciamento).

\section{Considerações finais}

O estudo aqui empreendido levantou algumas questões relacionadas à identidade semântica do marcador EM. De início, o aporte transcategorial deste trabalho afasta-se da rígida classificação das formas linguísticas em categorias estanques. EM e EN, abordados de maneira separada pelos trabalhos aqui apresentados como preposição e prefixo, são considerados unitariamente por serem, nos exemplos aqui discutidos, marcadores que remetem a operações equivalentes de localização espacial. Em segundo lugar, a metodologia da TOE levou-nos a uma tentativa de descrição mais precisa das diversas representações espaciais implicadas pelo uso de EM, dentre as quais distinguimos as de interioridade, contato, proximidade e gravitação. Comparada nossa descrição com a de Neves, que nos serviu de base fundamental, parece-nos que a diferença está em havermos contribuído para maior precisão taxionômica ao atentar para o valor gravitação e proximidade. Em terceiro lugar, diferentemente dos autores aqui referidos, propusemonos a explicar a razão pela qual o marcador EM implica as representações apontadas e não outras quaisquer, o que significa determinar os princípios organizadores que presidem a elaboração de tais representações, e, logo, a propriedade que configura a identidade semântica de EM. 
Como já afırmamos, a identidade de um item decorre do jogo observado no próprio modo como ele se integra ao cotexto enunciativo. Ora, a hipótese de que há uma propriedade imã intrínseca a esse marcador mostrou ter, nesse sentido, grande valor heurístico na medida em que, por ela, pôde-se explicar a (im)possiblidade de alguns enunciados, o que é revelador com respeito ao funcionamento dos itens preposicionais enquanto instauradores de uma relação específica entre termos postos em vinculação.

\section{REFERÊNCIAS}

CULIOLI, A. Pour une linguistique de l'énonciation tome 2. Formalisation et opérations. Paris: Ophrys, 1999a.

CULIOLI, A. Pour une linguistique de l'énonciation tome 3. Domaine notionnel. Paris: Ophrys, 1999b.

CULIOLI, A. Pour une linguistique de l'énonciation tome 1. Opérations et représentations. Paris: Ophrys, 1990.

CUNHA, C.; CINTRA, L. Nova gramática do português contemporâneo. 3. ed. Rio de Janeiro: Lexikon, 2001.

DE VOGUÉ, S.; FRANCKEL, J.-J.; PAILLARD, D. Linguagem e enunciação: representação, referenciação e regulação. São Paulo: Contexto, 2011.

FRANCKEL, J.-J.; PAILLARD, D. Grammaire des prépositions. T. 1. Paris: Ophrys, 2007.

HOUAISS, A. Dicionário eletrônico Houaiss da língua portuguesa. Rio de Janeiro: Objetiva, 2009.

LIMA, C. H. da R. Gramática Normativa da Língua Portuguesa. Rio de Janeiro: José Olympio, 2003.

NEVES, M. H. de M. Gramática de usos do português. São Paulo: Editora UNESP, 2011.

PAILLARD, D. Prépositions et rection verbale, 2002. Disponível em: https://www.cairn.info/ revue-travaux-de-linguistique-2002-1-page-51.htm. Acesso em: 05 jul. 2019. 
ROMERO-LOPES, M. C. Processos enunciativos de variação semântica e identidade lexical: a polissemia redimensionada. 2000. Tese (Doutorado em Língua e Literatura Francesa) - Faculdade de Filosofia, Letras e Ciências Humanas, Universidade de São Paulo, São Paulo, 2000.

ROMERO, M. Le fonctionnement sémantique de la préposition POR en portugais brésilien. Faits de Langues, Les Cahiers, Paris: Ophrys, n. 3, p. 209-232, 2011.

ROMERO, M. Processos enunciativos e identidade semântica da preposição POR. Cadernos do IL, Porto Alegre, n. 46, p. 149-170, 2013.

ROMERO, M.; TRAUZZOLA, V. S. L. Identidade lexical, funcionamento enunciativo e variação semântica para a Teoria das Operações Enunciativas. Calidoscópio, Rio Grande do Sul, v. 12, n. 2, p. 239-248, 2014.

ROMERO, M.; VILELA, T. R. O uso interproposicional de POR em uma descrição unitária de funcionamento da preposição. In: DIAS, L. F. et ali. (org.). Enunciação e materialidade linguística. Belo Horizonte: Ed. UFMG, 2015.

ROMERO, M. Léxico, invariancia y actividad de lenguaje. In: GARCÍA-MOLINS, A. L.; JIMÉNEZ, D. J. (ed.). Enacción y léxico. Valencia: Tirant Humanidades, 2017.

VILELA, T. R. Educação léxico-gramatical: um estudo semântico-enunciativo da preposição COM. 2016. Dissertação (Mestrado em Educação e Saúde na Infância e na Adolescência) - Faculdade de Filosofia, Letras e Ciências Humanas, Universidade Federal de São Paulo, São Paulo, 2016.

VILELA, T. R.; ROCHA, E. G. L. Um breve panorama: descrição e abordagem metodológica de preposições no português brasileiro. Estudos Linguísticos, São Paulo, v. 46, n. 1, p. 296-310, 2017. 